\title{
Recurrent Spontaneous Abortions: An Overview of Genetic and Non-Genetic Backgrounds
}

\author{
Aruna Meka and B. Mohan Reddy* \\ Biological Anthropology Unit, Indian Statistical Institute, 203 Barrackpore Trunk Road, \\ Kolkata 700 108, West Bengal, India
}

KEYWORDS Recurrent spontaneous abortions; HLA and other genes associated; psychosomatics; abortions in India

\begin{abstract}
Recurrent Spontaneous Abortion (RSA), Habitual Abortion or Habitual Miscarriage is the loss of 3 or more consecutive pregnancies before the $24^{\text {th }}$ week of gestation. RSA occurs chiefly due to either a problem with the pregnancy or when there is a problem in the environment where it implants and further development occurs. 10-15 $\%$ of women with recurrent early pregnancy loss have congenital uterine abnormalities. The role of infections, hormonal imbalances, nutritional deficiencies, and grief has been studied but the results are contradictory from one study to the other suggesting a need of further study. Genetic basis of RSA is poorly understood. Single gene mutations, polygenic, and cytogenetic factors are all found to show association with RSA. In approximately $2-4 \%$ of couples with recurrent pregnancy loss, one partner will have a genetically balanced structural chromosome rearrangement. This review looks into the various factors associated with RSA in the West and in the work done in this area in India. It also emphasizes on the need for an appropriately designed framework to study the various aspects of RSA.
\end{abstract}

\section{INTRODUCTION}

'There are few subjects of such clinical importance as recurrent miscarriage so bedevilled by inconsistency, imprecision and unwarranted assumption. This applies particularly to the fundamental question of etiology in which physicians all too frequently confuse "association" with "cause".'

Stirrat GM, 1992.

Recurrent Spontaneous Abortions (RSA) of unknown etiology provides a fundamental insight into the processes of embryogenesis and implantation and is also a frustrating and emotionally charged clinical problem. Under the best of circumstances, the reproductive process in humans is quite inefficient, as approximately $70 \%$ of fertilized ova are lost. Spontaneous Abortion is one of the least understood pathological processes in spite of being one of the most common symptoms. In $50 \%$ or more of couples with RSA an evaluation including parental karyotypes, hysterosalphingography or hystero-scopy and antiphospholipid antibody testing will be negative. Therefore, a majority (approximately 50 $-75 \%$ ) of couples with RSA will have no certain

*Corresponding Author: Prof. Dr. B. Mohan Reddy, Biological Anthropology Unit, Indian Statistical Institute, Street No. 8, Habsiguda, Hyderabad 500 007, Andhra Pradesh, India

Telephone: 040-27153984 (Office)

Fax: 040-27173602 / 27179402

E-mail: bmr@isical.ac.in diagnosis. Facts regarding the frequency, familial distribution and relation to parity and parental age in this issue are either unknown or disputable due to the difficulty in obtaining reliable information.

\section{WHAT IS RSA?}

The classic definition of RSA is the loss of 3 or more clinically recognized pregnancies spontaneously during early gestation. The modern definition, however, is the spontaneous loss of 2 or more consecutive pregnancies before 20 weeks of gestation, which takes into consideration that a woman over 35 is at greater risk for pregnancy loss than a 25 year-old woman (http://www.rbaonline.com/recurrentloss.asp). The World Health Organization (WHO) has defined a miscarriage as the loss of a fetus or embryo weighing $\leq 500 \mathrm{~g}$, which would normally be at 20-22 complete weeks of gestation (WHO 1977). Recurrent Miscarriage, synonymously used with RSA, Habitual Abortion or Habitual Miscarriage is defined as the loss of 3 or more consecutive pregnancies before the $24^{\text {th }}$ week of gestation (Reiss 1998).

\section{How Common is RSA?}

It is estimated that fetal viability is achieved only in $30 \%$ of all human conceptions, $50 \%$ of which are lost prior to the first missed menses (Edmonds et al. 1982). In humans, approximately $25 \%$ of implanted embryos are resorbed within 
7-14 days after attachment to the uterine endometrium (Baines and Gendron 1993). The loss of clinically recognized pregnancies prior to the $20^{\text {th }}$ week of gestation occurs at a frequency of $15 \%$ (Alberman 1988; Warburton and Fraser 1963).

The physical, emotional and financial toll of pregnancy loss is large. The emotional issues surrounding pregnancy loss become magnified exponentially when miscarriage occurs on a repetitive basis. Studies suggest that, by statistical 'bad luck' alone, 4-6\% of all women attempting pregnancy will experience at least two miscarriages, and about $1-2 \%$ will have 3 or more miscarriages (Feinberg 1997). Some studies suggest that clinical intrauterine pregnancy losses occur in 12-14\% of all pregnancies (Regan et al. 1989; Wilcox et al. 1988) and can be attributed to random factors (often fetal de novo chromosomal abnormalities). The number of women with RSA for non-recurrent reasons will decline exponentially with the number of previous miscarriages, because their risk of a new miscarriage in their fourth or fifth pregnancy is still only $14 \%$ compared with the $35-50 \%$ risk in the whole group of RSA patients with a similar number of previous miscarriages (Cauchi et al. 1995). Patients with a systemic problem will comprise an increasingly larger fraction of all RSA patients with an increased number of previous pregnancy losses.

\section{RSA and Major Causes}

RSA is defined by repeated occurrence of miscarriage. There are 2 major reasons for RSA. Either there is something wrong with the pregnancy itself, such as chromosomal abnormality that prohibits the pregnancy from implanting/growing properly or there is a problem within the environment in which the pregnancy grows.

Problems with the Pregnancy: Implantation usually occurs after 8-10 days of ovulation in most healthy pregnancies. The proportion ending in early loss increases when implantation is later than this period. Chromosomal abnormalities in the conceptus are usually the characteristic findings in cases of spontaneous abortions occurring due to problems with the pregnancy itself. Chromosomal abnormalities occur in about $50 \%$ of all products of conception from first trimester miscarriages, $5 \%$ of late pregnancy losses and $0.5 \%$ of livebirths (www.haveababy. $\mathrm{com} / \mathrm{rpl} /$ causes.asp? site=rpl). Abortions due to trisomy have a high risk of repeating followed by monosomy and polyploidy. Biochemical or clinical abortion occurs in 30-40\% of women who achieve pregnancy after in vitro fertilization (IVF) and embryo transfer (ET). Structural rearrangements are found in $3 \%$ of cytogenetically abnormal conceptions (Boue et al. 1975).

When embryonic or fetal tissue is available and the crown-rump length is at least $30 \mathrm{~mm}$, morphologic examination can predict the karyotype in more than $98 \%$ of cases. Some $33 \%$ of all malformed fetuses and $66 \%$ of malformed embryos have chromosomal abnormalities (Stirrat 1983). Studies suggest existence of paternal (sperm derived) effect on human embryo quality and pregnancy outcome that are not reflected as a chromosomal abnormality. Damaged sperm DNA can have a negative impact on fetal development and present clinically as occult or early clinical miscarriage (www.haveababy.com/rpl/ causes.asp? site $=\mathrm{rpl})$.

Problems with the Environment: Problems in the environment, in which the fetus grows after implantation, include chromosomal abnormalities, autoimmune disorders, endocrine anomalies, anatomic defects, defects in enzymes catalysing various metabolic pathways, endometriosis, hormonal imbalances and nutritional deficiencies in the mother. The problems involved are thus classified under the broad titles as anatomic, hormonal and metabolic, nutritional, psychological, infectious, genetic and immunologic/ immunogenetic.

Anatomic Uterine Defects: Anatomical investigations are normally performed by hysterosalphingography, hysteroscopy or ultrasound scans. Mullerian duct fusion anomalies in the uterus have traditionally been considered responsible for cases of RSA and premature deliveries. Congenital uterine abnormalities have been associated most often with $2^{\text {nd }}$ trimester pregnancy loss. However, 10-15\% of women with recurrent early pregnancy loss have congenital uterine abnormalities (<http:/www.modem/com/ search/article_display.cm?path=IITANQUERAY IM.ContentItem\&mstr=M_ContentItemZZZSJ24 MUJC.html\&soc=ACOG \&srch_type+NAV_ SERCH $>$ )The most common malformations associated with RSA are variations of the double uterus (bicorunate, septate or didelphic) with septate uterus predominating. Anatomic abnormalities include uterine abnormalities like double 
uterus, or uterine adhesions as in the case of Asherman's syndrome; presence of endometrial polyps, sub mucous fibroids and mullerian duct defect.

Some investigators believe that poor vascularisation of the uterine septum is a cause of spontaneous abortion, but studies provide mixed results. Uterine leiomyomata are usually asymptomatic during pregnancy, but circumstantial evidence suggests an association with an increase in threatened miscarriage and preterm labor. The mechanism of pregnancy loss may involve changes in blood flow and placental abruption is also common with submucous myomata.

Hysteroscopic myomectomy is advocated to remove pedunculated and small submucous fibroids. Women with a diagnosis of cervical insufficiency are often treated by a cervical cerclage (McDonald 1987). The efficacy of this intervention has been studied in three randomized control trials; none could demonstrate any significant effect with respect to decreasing perinatal mortality, in patients with at least three previous $2^{\text {nd }}$ trimester miscarriages or stillbirths (Rush et al. 1984; Winisdoerffer et al. 1989). In a study carried out among 208 couples with Bad Obstetric History referred from hospitals in and around Bangalore (Srinivas and Rajangam 2001) anatomic causes were observed in 8 women. Most of the losses observed by this group were in the second trimester as seen in $\mathrm{BOH}$ patients with an anatomical defect.

Hormonal and Metabolic Disorders: Hormonal factors have been proposed to contribute to RSA in 10-20\% of patients (http: / /www.haveababy.com/rpl/causes.asp?site=rpl). Hormonal aberrations may result from problems with certain endocrine glands, such as the pituitary, thyroid, adrenal gland or ovaries. Ovulation problems resulting in deficient hormone levels may cause aberrant growth and support of the uterine lining resulting in a less-than-ideal "bed" for the embryo to implant in. Luteal Phase Defect (LPD) has been thought to be a cause of spontaneous abortions for decades, but the evidence linking LPD to recurrent abortion is subject to criticism. If a luteal phase endometrial biopsy is out of phase for $>2$ days or serum progesterone concentration measurements are below defined values, then it is often diagnosed as luteal phase defect or luteal insufficiency. LPD implicates poor follicular phase oocyte development, which results in disordered estrogen secretion and subsequent dysfunction of either the corpus luteum or progesterone effect. The most popular therapy is progesterone supplementation. Poly Cystic Ovary Syndrome (PCOS) and type I Diabetes Mellitus (Dorman et al. 1999) has also been found to be associated with RSA. Poly Cystic Ovary Syndrome causes menstrual disorders ranging from amennorhea to dysfunctional uterine bleeding, hirsutism and infertility. An elevated level of LH in PCOS is thought to be responsible for its role in RSA. Asymptomatic endocrinologic or metabolic disorders such as mild thyroid disease or glucose intolerance show little evidence towards an association with RSA.

Nutritional Causes: In a study conducted to explore the relationship between maternal health status and infant vitality, selected physical, nutritional, and biochemical parameters were measured in 157 pregnant women and 71 newborn infants at the Azimpur Maternity Center in India (Hussain et al. 1976). The third trimester hemoglobin levels in these women averaged $10.53 \%$ during first pregnancy, $9.84 \%$ in second pregnancy, $10.04 \%$ in third and $10.36 \%$ in fourth pregnancy. The average total protein and packed cell volume remained relatively constant with increases in parity. The prevalence of combined moderate and severe anemia was averaging within $41.2 \%$ to $48 \%$ in these women during each of their pregnancies. Overall, $66 \%$ of the women had hemoglobin levels below $11 \mathrm{gm} \%$ and could be considered anemic. The increased incidence of anemia with increasing parity is attributed to the gradual drain on maternal nutritional reserves. Other than the rate of anemia the serum concentrations also are considered to play a major role. The deficiency of vitamin A is a cause of increased infant mortality (Sharma and Desai 1992). Low concentrations of dietary and circulating folate are associated with increased risks of preterm delivery, infant low birth weight, and fetal growth retardation. A metabolic effect of folate deficiency is an elevation of blood homocysteine. The presence of maternal homocysteine concentrations have been associated both with increased habitual spontaneous abortion and pregnancy complications (eg, placental abruption and preeclampsia), which increase the risk of poor pregnancy outcome and of decreased birth weight and gestation duration (Scholl and Johnson, 2000).

Based on their experience in cases of RSA, 
some clinicians feel that the intake of fresh food like sprouts, fruits, raw vegetables is likely to improve the pregnancy outcome when compared with those taking processed food (personal communication with Dr. Sadaranga Andal). A study needs to be carried out to find out the reasons behind this.

Infections as a Cause: Clinicians suggest that if the uterine lining is infected or inflammed, then it would be a hostile environment for an embryo to implant and grow properly. Microorganisms like Toxoplasmosis, Listeria, Cytomegalovirus and parvovirus are known to cause sporadic pregnancy loss, but no infectious agent has been proven to cause RSA. Other infectious agents include Brucellosis, Mycoplasma, Uroplasma, Chlamydia etc., though a proven relationship with recurrent abortion has not been established. Herpes Simplex Virus has been linked to Spontaneous Abortion and Chronic HSV is a possible cause of RSA. Fetal infection may lead to either fetal death or malformations incompatible with viability. Amnionitis in the first trimester may also cause pregnancy loss.

\section{GENETIC CAUSES}

\section{i) Analysis of Couples}

Genetic basis of RSA is poorly understood. Single gene mutations, polygenic, and cytogenetic factors are all found to show association with RSA. The analysis of single nucleotide polymorphisms in the genes coding for: 1) enzymes with regulatory role in crucial metabolic pathways (e.g. methylene tetra hydrofolate reductase), 2) clotting factors (Factor $\mathrm{V}$ leiden and prothrombin), 3) hormones and hormone receptors (progesterone receptor) explain some cases of Spontaneous Abortions.

1) MethyleneTetraHydroFolate Reductase (MTHFR) and Transcobalamine: Polymorphisms in MTHFR $(677 \mathrm{C} \rightarrow \mathrm{T}$ and $1298 \mathrm{~A} \rightarrow \mathrm{C}$ ) and Transcobalamine $(776 \mathrm{C} \rightarrow \mathrm{G})$ genes lead to a defect in folate and vitamin B12 dependent homocysteine metabolism (Zetterberg 2004). These polymorphisms implicate as risk factors for several developmental disorders such as NTD, orofacial clefting and Down's syndrome. Vitamin B12 deficiency during pregnancy results in elevated homocysteine concentration in the embryo and increases the incidence of NTD. Hereditary deficiency of transcobalamine results in profound neurological abnormalities and mental retardation. The molecular events that lead to NTD may include insufficient methylation of crucial metabolites in the developing embryo and abnormalities in neural cell proliferation, differentiation and apoptosis, which may be due to DNA nucleotide misincorporation that accompanies folate deficiency in proliferating decreased fetal viability.

2) Clotting Factor Mutations: Factor V Leiden and Prothrombin G 20210 A mutations found in approximately $8 \%$ and $3 \%$ respectively of Caucasian women in the US are associated with approximately $25 \%$ of isolated thrombotic events and approximately $50 \%$ of familial thrombosis. Other less common thrombophillias include deficiency of the anticoagulants Protein C, Protein S and antithrombin III. Some investigators have found one or more of these thrombophillic mutations associated with RSA.

3) Skewed X Chromosome Inactivation $(X C I)$ : An increase in extremely skewed XCI of $\geq$ $90 \%$ has been reported among women who experience RSA (Sangha et al 1999; Lanasa et al 1999, 2001; Uehara et al 2001). Because there are many potential causes of skewed XCI, the reason for an association between RSA and skewed XCI is not clear and may be heterogeneous. A significant excess of trisomic losses was observed among the women who had RSA with skewed XCI versus those without skewed XCI. X linked mutations (deletions, translocations etc) have been clearly associated with skewed XCI and RSA in some families (Pegoraro et al 1997). Molecular study reveals a deletion on Xq28 as one of the causes of skewed XCI. One report indicated that highly skewed X-chromosome inactivation is associated with otherwise unexplained recurrent pregnancy loss. As yet, however, commercially available tests for this and other related molecular genetic abnormalities are not widely available.

4) Progesterone Receptor Gene: Progesterone is required for the maintenance of pregnancy and many times treatment with progesterone supplementation prevents abortions. Three linked single nucleotide polymorphisms were detected (Schweikert et al. 2004) in the progesterone receptor gene-exon 1: G $1031 \mathrm{C}$; Ser 344 Thr, exon 4: G 1978 T; Leu 660 Val, exon 5: C $2310 \mathrm{~T}$; His 770 His.

Several other variations caused by singlegene mutations (Mendelian disorders) or muta- 
tions at several loci (polygenic or multifactorial disorders) which cannot be detected by karyotype analysis are however, being identified with the aid of molecular biological techniques such as florescence in situ hybridization, polymerase chain reaction, restriction fragment length polymorphism's.

Work has only just begun on molecular mechanisms (e.g., structure and function of cell adhesion molecules, proteins involved in immune responses) that may be responsible for recurrent pregnancy loss. In anembryonic pregnancies, molecular genetic techniques using microsatellite and $\mathrm{Y}$-specific probes can demonstrate both maternal and paternal contributions. Treatment of parental chromosome abnormalities is overcome by explanation after future risk assessment and by the use of donor eggs/sperm, or adoption. In approximately $2-4 \%$ of couples with recurrent pregnancy loss, one partner will have a genetically balanced structural chromosome rearrangement. A study by Bhasin et al (1973) reports that of the 27 women studied one showed a translocation and of the 16 husbands studied one showed a pericentric inversion. Balanced translocations account for the largest percentage of these karyotypic abnormalities. They can cause pregnancy loss because segregation during meiosis results in gametes with duplication or deficiency of chromosome segments. Other genetically balanced structural chromosome abnormalities, such as chromosome inversions, account for a small percentage of abnormal parental karyotypes among couples with recurrent pregnancy loss. Thus routine Cytogenetic testing fails to render a complete picture in $98 \%$ of couples, who are cytogenetically normal (Thomas 1999; Patel et al. 2000). Damaged sperm DNA, genes predisposing to ovarian cancer; breast cancer; apoptotic genes like Caspase 3-12, CathespinH, FasL (Baek 2004) and tumor suppressor genes etc are also found to increase the incidence of RSA. Immunity and angiogenesis related genes like PP14, hCG, leukaemia inhibitory factor, integrin etc, involved in RSA have also been reported (Baek 2004).

\section{ii) Recurrent Preembryonic or Embryonic Aneuploidy and Translocations}

Analyses of karyotypes in consecutive abortions suggest that recurrent aneuploidy in the conceptus may be a cause of recurrent preg- nancy loss. In one analysis of data, the karyotype of a second successive spontaneous abortion was abnormal in nearly $70 \%$ of cases when aneuploidy was found in the first abortus, but in only $20 \%$ of cases where the first abortus was chromosomally normal (Hassold 1980). The older age of the mothers is a possible reason to this finding (Warburton et al. 1987). More recently, two groups of investigators have shown using different techniques of analysis, that the next abortion in women with recurrent pregnancy loss was chromosomally abnormal in $48 \%$ or more of cases (Daniely et al. 1998; Stern et al. 1996), raising the possibility of recurrent aneuploidy despite normal parental karyotypes. Supportive evidence comes from studies of preimplantation genetic studies of women with recurrent pregnancy loss in which more than $50 \%$ of embryos were found to have aneuploidy (Vidal et al. 1998; Simon et al. 1998). Of the familial translocations, about $66 \%$ are maternally derived and the remaining are of paternal origin. Approximately $50 \%$ of all unbalanced translocations arise de novo during gametogenesis. The risk of delivering a live fetus with trisomy 21 is $10 \%$ to $15 \%$ if the mother carries the anomaly and $2 \%$ for a paternal carrier; approximately $50 \%$ of these concepti will be lost to spontaneous abortion. When the translocation involves chromosomes 13 and 14, the risk is $1 \%$ regardless of the parent involved. The birth of a trisomic infant increases the risk of a subsequent trisomic pregnancy by $1 \%$ (Boue et al. 1975).

Immunologic Causes: The main task of the immune system is to protect the individual from foreign microorganisms with the help of T- and B- lymphocytes, granulocytes, macrophages, monocytes and some non-cellular factors like Immmunoglobulins, complement factors, and interleukins.

The immune factors associated with pregnancy loss are classified as autoimmune and alloimmune factors. The autoimmune factors include the synthesis of autoantibodies (anti-phospholipid antibodies, anti nuclear antibodies, anti thyroid antibodies). Antiphospholipid syndrome (APS) is an autoimmune disorder characterized by the presence of significant levels of antiphospholipid antibodies and one or more clinical features, among which are recurrent pregnancy loss, fetal death, and thrombosis (Wilson et al. 1999). Alloimmune traits such as immunologic differences between individuals have been proposed as factors between reproductive partners 
that cause otherwise unexplained recurrent pregnancy loss. The tendency for 1) partners with recurrent loss to share human leukocyte antigens, 2) the female partner to fail to produce serum "blocking factor," and 3) the female partner to produce antileukocytotoxic antibodies against paternal leukocytes have been described.

The HLA genes are the main genetic determinants of the repertoire of possible immune responses of an individual. Human Leukocyte antigens (HLA) play critical role throughout pregnancy by influencing gamete development, embryo cleavage, blastocyst and trophoblast formation, implantation, fetal development and survival (Choudhury and Knapp 2000, 2001). In couples with RSA, where no certain diagnosis has been possible, Human Leukocyte antigens (which play crucial role in transplantations) might be playing a role at the maternal-fetal interface. The fetus being semi-allogenic might face a rejection from the maternal antibodies if there is increased HLA sharing among the couple.

HLA complex or MHC contains over 150 loci spanning approximately $4 \mathrm{Mb}$ of DNA on $6 \mathrm{p} 21$. The MHC is subdivided into 3 regions - Class- I, Class- II, and Class- III (Browning and Mcmichael 1996). HLA locus is a high gene density locus with a high frequency of gene rearrangements resulting in the formation of null alleles producing variant antigens or no antigen. HLA antigens play a major role in transplantation and are critical in pregnancy from gamete formation to completion of development. Class-I antigens express on the invasive trophoblast and play a role at the maternal-fetal interface. The results of studies in different populations in the west have revealed significant association of different alleles in each population. For example, studies by Pfeiffer et al (2001) suggest an increased frequency of HLA$\mathrm{G} * 01013$ and HLA-G $* 0105 \mathrm{~N}$ carriers in the RSA group compared to controls while a study by Aldrich et al (2001) suggests increased frequencies of the alleles HLA-G $* 0104$ or $* 0105 \mathrm{~N}$. Another study reveals that RSA patients carry HLA-G *0106 allele which exhibits a 14 bp deletion in exon 8 . This study reported that RSA women were homozygous for the 14 bp deletion but RSA men were low in frequency for the deletion (Hviid et al, 2002). In a case control study using the RFLP, the frequencies of the HLA-DRB1* 01 and HLA-DR* 03 allogenotypes were significantly increased among the patients with at least four previous miscarriages (Kruse et al
2004). Complement component $\mathrm{C} 4$ gene polymorphisms also are found to be associated with RSA. $\mathrm{C} 4 \mathrm{~A}$ null alleles increased in the primary abortions group wives and husbands compared to the controls and $\mathrm{C} 4 \mathrm{~B}$ null alleles show an increase in the secondary abortion wives and husbands compared to the controls. This study reports that $95 \%$ of primary abortion couples and $83 \%$ of secondary abortions couples had at least one C4A or C4B null in their phenotypes compared to $66 \%$ among controls (Laitinen et al 1991). HLAA, -B and -C loci were also studied but the results were not statistically significant. Thus, previous studies on association of HLA alleles (class-I, II, and -III) and HLA sharing among couples have been contradictory leaving scope for further study. Moreover, to the best of our knowledge, no study has been conducted in India to reveal the association of HLA alleles with RSA.

Psychological Factors: Not much of research is done to find out the role of grief in spontaneous abortions. A few groups have studied the role of grief in women who undergo abortion in the first trimester of an unintended pregnancy. A study suggests no increase in anxiety or depressive reactions two weeks after a first trimester abortion when these patients were compared with non pregnant healthy working women in the age group of 19-39 years (Nielsen et al, 1996). In a different study conducted on 882 women undergoing abortion of unintended pregnancies 442 were followed up to 2 years. This group reports that $72 \%$ of women felt they were benefited and $80 \%$ were not depressed. 1 $\%$ reported posttraumatic stress disorder. This group opines that prepregnancy depression is a risk factor for depression, lower self esteem and negative abortion specific outcomes 2 years post abortion (Bergant et al, 1997; Major et al 2000). But a few groups also express a completely contrasting opinion. On the basis of their study in women undergoing spontaneous abortions, Hall et al (1987) report grief as a common response to the event. Patients often report prolonged distress following the episode of spontaneous abortions. Symptoms seen in these patients include shock, denial, anger, anxiety, grief and depression. Components of grief comprise high levels of guilt, the loss of part of self and a large impact upon personal identity.

A study funded by United States Department of Labor, carried out between 1976-1992 on 12,686 young girls in the age group of 14- 21, reports 
that woman whose first pregnancy ended in abortion were $65 \%$ more likely to score in the high risk range for clinical depression than women whose first pregnancies resulted in birth (Cougle et al. 2003). Hofberg and Ward (2003) suggest that depressive illness is often associated with postnatal mothers but it is equally common in pregnant women. Consequences of postnatal depression to the child, mother and the family include neglect of the child, family breakdown and suicide. Studies reveal that infants may develop emotional or behavioral problems or cognitive delays in childhood (Murray et al. 1999; Sinclair and Murray 1998). The depressive symptoms include a fear of pregnancy, fear of pain and symptoms like eating disorders (anorexia nervosa, bulimia nervosa) are common in the childbearing years. Anorexia is reported to be antagonistic to reproduction and pregnancy is rare in active anorexia nervosa except where ovulation is induced (Morgan 1999). A higher rate of stillbirths is reported in these patients. Yet another review concludes that miscarrying women are at increased risk for anxiety symptoms immediately following miscarriage and continuing until approximately 4 months post-loss (Geller et al 2000). Reports on effects after 4 months are inconsistent. Based on her long interaction with the RSA women Dr. Sadaranga Andal (personal communication) strongly believes that counseling these women to avoid stress symptoms results in successful pregnancy in a number of cases. From the foregoing analysis of the existing data on the role of grief no clear conclusions emerge, hence the need for further investigations into this aspect.

\section{INDIAN SCENARIO}

In Indian culture, having a baby is a life changing experience for the couple. There is no reliable estimate of the magnitude of abortions that take place in India but studies suggest that as women in India do not have control on their fertility and have poor health, there are very high chances that they experience abortions (either spontaneous or induced) more than once. It is difficult to attain a reliable estimate on abortion frequencies in the Indian context as the registration of marriages, births and deaths are usually not complete. As mentioned earlier recurrent abortions affect the couple psychologically, emotionally and are a traumatic experience and many undergo treatment without actually knowing the cause. This is particularly true in Indian context. Child bearing in India is concentrated in the age group of 15-29, which contributes more than $3 / 4$ of total fertility. Current fertility is characterized by a substantial amount of early child bearing: $17 \%$ of total fertility is accounted for by births to women in the age group of 15-19 (NFHS-I summary report). A study was carried out on the obstetric behaviour and outcome in teenage mothers (Pal et al. 1997). Anemia (27.5\%), intrauterine growth retardation $(27.5 \%)$ and hypertension $(15 \%)$ were mostly found as complications in the study group compared to controls $(11.2 \%, 8.7 \%$, and $8.7 \%$ respectively). The association of Vitamin A levels (Sharma and Desai 1992) and serum folic acid levels with RSA (Dutta 1977) is studied. A few research groups have been working to determine the extent of maternal infection with Toxoplasma Gondii responsible for reproductive disorders (Oumachigui et al. 1980; Pal and Agarwal 1979). Jalan (http: //jalananil.tripod.com/NIRMAN/ id12.html) suggests that in Indian situation we still do not have the abortus material available for chromosomal studies. Abortus studies would pickup chromosomal abnormalities in approximately $40-50 \%$ of cases as against this we have parental karyotyping, where the pickup rate is not above $6 \%$ in a couple. This study also quotes studies by Panthaki et al. (1999), which suggests a $2 \%$ incidence of numerical aberrations among the couples.

Apart from these isolated studies restricted to certain parts of India there has not been much work in this area. Further, studies on spontaneous abortions in India have not been looked upon independently. In most of the studies patients with spontaneous as well as induced abortions have been combined together and the results therefore do not give a true picture of the causes and their frequency. Further, disruption of interacting factors, including interactions between HLA antigens, cytokines and natural killer (NK) cells are all expected to play crucial role in RSA. Excess sharing of HLA antigens between spouses has been considered by some to be a mechanism leading to maternal hyporesponsiveness to paternal antigens encountered in pregnancy and therefore subsequent miscarriage (Beer et al, 1981). Grief is also thought to be a potential abortogen. In order to attain a clear understanding of the causes of RSA in the 
Indian context, all the above aspects, which are hitherto unexplored, need to be investigated using appropriate framework.

\section{REFERENCES}

Alberman E 1988. The epidemiology of repeated Abortion. In: RW Beard and F Sharp (Ed): Early Pregnancy Loss: Mechanisms and Treatment. New York: Springer-Verlag pp. 9 -17.

Aldrich CL, Stephenson MD, Karrison T, Odem RR, Branch DW, Scott JR, Schreiber JR, Ober C 2001. HLA-G genotypes and pregnancy outcome in couples with unexplained recurrent miscarriage. $\mathrm{Mol}$ Hum Genet, 7: 1167-1172.

Baek KH 2004. Aberrant gene expression associated with recurrent pregnancy loss. Mol Hum Reprod, 10: 291-297.

Baines MG, Gendron RL 1993. Natural and experimental animal models of reproductive failure. In: $\mathrm{G}$ Chaouat (Ed.): Immunology of Pregnancy. Boca Raton: CRC Press pp. 173-203.

Beer AE, Qqebbman JF, Ayes JWT, Haines RF 1981. Major histocompatibility complex antigens, maternal and paternal immune responses and chronic habitual miscarriage. Am J Obstet Gynecol, 141: 987-999.

Bergant AM, Reinstadler K, Moncayo HE, So"lder E, Heim K, Ulmer H, Hinterhuber H, Dapunt O 1997. Spontaneous abortion and psychosomatics. A prospective study on the impact of psychological factors as a cause for recurrent spontaneous abortion. Human Reprod, 12: 1106-1110.

Bhasin MK, Foerster W and Fuhrmann W 1973. A cytogenetic study of recurrent abortion. Humangenetik, 18: 139-48.

Boue J, Boue A, Lazar P 1975. Retrospective and prospective epidemiological studies of 1500 karyotyped spontaneous human abortions. Teratology, 12: 11-26.

Browning M, McMichael A 1996. Introduction In: M Browning and A McMichael (Ed.): HLA and MHC: Genes, Molecules and Function. Oxford, UK: BIOS Scientific publishers pp. xiii - xviii.

Cauchi MN, Coulam CB, Cowchock S, Ho HN, Gatenby P, Johnson PM, Lubs MLE, McIntyre JA, Ramsden GH, Smith JB, Sharpe K 1995. Predictive factors in recurrent spontaneous aborters - a multicenter study. Am J Reprod Immunol, 33: 165-170.

Choudhury SR, Knapp LA 2000. Human reproductive failure I: Immunological factors. Hum Reprod Update, 7: 113-134.

Choudhury SR, Knapp LA 2001. Human reproductive failure II: Immunogenetic and interacting factors. Hum Reprod Update, 7: 135-160.

Cougle JR, Reardon DC, Coleman PK 2003. Depression associated with abortion and childbirth: a longterm analysis of the NLSY cohort. Med Sci Monit, 9: CR157-164.

Daniely M, Goldring AA, Barkai G, Goldman B 1998. Detection of chromosomal aberration in fetuses arising from recurrent spontaneous abortion by comparative genomic hybridization. Hum Reprod, 13: $805-809$.
Definition of Recurrent Pregnancy Loss (online) (last updated October 27th, 2004) <http: //www.rbaonline.com/recurrentloss.asp >

Dorman JS, Burke JP, McCarthy BJ, Norris JM, Steenkiste AR, Aarons JH, et al. 1999. Temporal trends in spontaneous abortion associated with Type 1 diabetes. Diabetes Res Clin Pract, 43: 41-47.

Dutta GP 1977. Serum folic level in abortion. J Indian Med Assoc, 69: 149-153.

Edmonds DK, Lindsay KI, Miller JF 1982. Early embryonic mortality in women. Fertil Steril, 38: $447-453$.

Feinberg RF 1997. Medical Spotlight. Pregnancy loss: approaches to evaluation and treatment. (online) <http: //www.obgyn.net/displayarticle.asp?page=/ infertility/articles/feinberg_spotlight>

Geller PA, Kerns D, Klier CM 2000. Anxiety following miscarriage and the subsequent pregnancy: A review of the literature and future directions. Journal of Psychosomatic Research, 56: 35-45

Hall RC, Beresford TP, Quinones JE 1987.Grief following spontaneous abortion. Psy Clin North Am, 10: 405420.

Hassold TJ 1980. A cytogenetic study of repeated spontaneous abortions. Am J Hum Genet, 32: 723730

Hofberg K, Ward MR 2003. Fear of pregnancy and child birth. PMJ, 79: 505-510

Hussain MA, Khan AK, Abedin Z, Ferdous Z, Ahmad K 1976. Studies on the nutritional status of expectant mothers and newborn babies. Bangladesh Med Res Counc Bull, 2: 120-126.

Hviid TV, Hylenius S, Hoegh AM, Kruse C, Christiansen OB 2002. HLA-G polymorphisms in couples with Recurrent Spontaneous Abortions. Tissue Antigens, 60: $122-132$.

Jalan AB (online) <http: //jalananil.tripod.com/NIRMAN/ id12.html>

Kruse C, Steffensen R, Varming K, Christiansen OB 2004. A study of HLA-DR and -DQ alleles in 588patients and 562 controls confirms that HLA DRB $1 * 03$ is associated with Recurrent Miscarriage. Hum Reprod, 19: $1215-1221$

Laitinen T, Lokki ML, Tulppala M, Ylikorkala O, Koskimies S 1991. Increased frequency of Complement C4 'null' alleles in Recurrent Spontaneous Abortions. Hum Reprod, 6: 1384-1387.

Lanasa MC, Hogge WA, Kubic C, Blancato J, Hoffman EP 1999. Highly skewed X-chromosome inactivation is associated with idiopathic recurrent spontaneous abortion. Am J Hum Genet, 65: 252-254

Lanasa MC, Hogge WA, Kubik CJ, Ness RB, Harger J, Nagel T, Prosen T, Markovic N, Hoffman EP 2001. A novel X chromosome linked genetic cause of Recurrent Spontaneous Abortion. Am J Obstet Gynaecol, 185: 563-568.

Major B, Cozzarelli C, Cooper ML, Zubek J, Richards C, Wilhite M, Gramzow RH, 2000. Psychological Responses of Women After First-Trimester Abortion. Arch Gen Psychiatry, 57: 777-784.

McDonald IA 1987. Cervical incompetence as a cause of spontaneous abortion. In: MJ Mennett and DK Edmonds (Ed.): Spontaneous and Recurrent Abortion. Oxford, UK: Blackwell Scientific pp. 168-192. 
Medical library, ACOG (online) <http:/www.medem.com/ search/article_display.cfm? path=\ITANQUERAY M ContentItem\&mstr=M ContentItemZZZSJ24 MÜJC.html\& soc=ACOG\&srch_typ=NAV_SERCH>

Morgan JF 1999. Eating disorders and reproduction. Aust N Z J Obstet Gyneacol, 39: 167-73.

Murray L, Sinclair D, Cooper P 1999. The socioemotional development of 5 year olds with postnatally depressed mothers. J Child Psychol Psychiatry, 40: 1259-1271.

Newsletter on web by Sher Institute for Reproductive Medicine (online) <http: //www.haveababy.com/rpl/ causes.asp? site $=$ rpl>

Nielsen S, Hahlin M, Moller A, Granberg S 1996. Bereavement grieving and psychological morbidity after first trimester spontaneous abortion: comparing expectant management with surgical evacuation. Hum Reprod, 11: 1767-1770.

Oumachigui A, Bhatia VN, Nayak PN 1980. Toxoplasma antibodies and fetal wastage. Indian J Med Res, 71: 522-5.

Pal MN and Agarwal DS 1979. Toxoplasmosis and abortion. J Obstet Gynaecol India, 29: 59-61.

Pal A, Gupta KB, Randhawa I 1997. Adolescent pregnancy: a high-risk group. J Indian Med Assoc, 95:127-128

Patel ZM, Sanghavi DA, Adhia RA 2000. Chromosomal rearrangements amongst couples with recurrent abortions in Indian population. The Journal of Clinical Genetics and Tribal Research, 5: 41-49.

Pegoraro E, Whitaker J, Rushton PM, Surti U, Lanasa M, Hoffman EP 1997. Familial Skewed X inactivation: a molecular trait associated with high spontaneous abortion rate maps on Xq28. Am $J$ Hum Genet, 61: 160 - 170.

Pfeiffer KA, Fimmers R, Engels G, Van der Ven H 2001. The HLA-G is potentially associated with idiopathic Recurrent Spontaneous Abortions. Mol Hum Reprod, 7: 373-378.

Regan L, Braude PR, Trembath PL 1989. Influence of past reproductive performance on risk of spontaneous abortion. $\mathrm{Br}$ Med J, 299: 541-545.

Reiss HE 1998. Reproductive Medicine: From A to Z. Oxford: Oxford University Press.

Rush RW, Isaacs S, McPherson K et al. 1984. A randomized controlled trial of cervical cerclage in women at high risk of spontaneous pre-term delivery. Br J Obstet Gynaecol, 91: 724-730.

Sangha KK, Stephenson MD, Brown CJ, Robinson WP 1999. Extremely skewed X-Chromosome Inactivation is increased in women with Recurrent Spontaneous Abortions. Am J Hum Genet, 65: 913917.

Scholl TO and Johnson WG 2000. Folic acid: influence on the outcome of pregnancy. American Journal of Clinical Nutrition, 71: 1295-1303.

Schweikert A, Rau T, Berkholz A, Allera A, Daufeldt S, Wildt L 2004. Association of progesterone receptor polymorphism with recurrent abortions. Eur $J$ Obstet Gynecol Reprod Biol, 113: 67-72.

Sharma R, Desai S 1992. Vitamin A in pregnancy: a review. Indian J Matern Child Health, 3(2): 36-40. Simon C, Rubio C, Vidal F, Gimenez C, Moreno C, Parrilla JJ 1998. Increased chromosome abnormalities in human pre-implantation embryos after in-vitro fertilization in patients with recurrent miscarriage. Reprod Fertil Dev, 10: 87-92

Sinclair D, Murray L 1998. Effects of postnatal depression on children's adjustment to school. $\mathrm{Br} J$ Psychiatry, 172: 58-63.

Srinivas N and Rajangam S 2001. Anatomical Causes of Bad Obstetric History. J Anat Soc India, 50(2): 119-121.

Stern JJ, Dorfmann AD, Gutierrez-Najar AJ, Cerrillo M, Coulam CB 1996. Frequency of abnormal karyotypes among abortuses from women with and without a history of recurrent spontaneous abortion. Fertil Steril, 65: 250-253.

Stirrat GM 1983. Recurrent abortion a review. Br J Obstet Gynaecol, 90: 881-882.

Thomas IM 1999. Cytogenetic basis of recurrent abortion. Paper presented in the Dr. I.D. Sanghavi oration at $29^{\text {th }}$ National Conference of Indian Society of Human Genetics, Mumbai.

Uehara S, Hashiyada M, Sato K, Sato Y, Fujimori K, Okamura K 2001. Preferential X Chromosome Inactivation in women with idiopathic Recurrent Pregnancy Loss. Fertil Steril, 76: 908-914.

Vidal F, Gimenez C, Rubrio C, Simon C, Pellicer A, Santalo J 1998. FISH pre-implantation diagnosis of chromosome aneuploidy in recurrent pregnancy wastage. J Assist Reprod Genet, 15: 310-313.

Warburton D and Fraser FC 1963. Spontaneous abortion rate in man: data from reproductive histories collected in a medical genetics unit. Am J Hum Genet, 16: 1-28

Warburton D, Kline J, Stein Z, Hutzler M, Chin A, Hassold A 1987. Does the karyotype of a spontaneous abortion predict the karyotype of a subsequent abortion? Evidence from 273 women with two karyotyped spontaneous abortions. Am J Hum Genet, 41: 465-483.

Wilcox AJ, Weinberg CR, O'Connor JF (1988) Incidence of early loss of pregnancy. N Engl J Med, 319:188194

Wilson R, Ling H, MacLean MA, Mooney J, Kinnane D, McKillop JH et al 1999. Thyroid antibody titer and avidity in patients with recurrent miscarriage. Fertil Steril, 71: 558-561.

Winisdoerffer G, Lazar P, Papiernik E 1989. The controlled trial of cervical cerclage. In: Papiernik E, Keith LG, Bouyer J et al. (Ed.): Effective Prevention of Pre-Term Birth: The French Experience Measured at Haguenau, 25: 139-147.

World Health Organisation 1977. Recommended definitions, terminology and format for statistical tables related to perinatal period. Acta Obstet Gynecol Scand, 56: 247-253.

Zetterberg H, 2004. Methylenetetrahydrofolate reductase and transcobalamin genetic polymor-phisms in human spontaneous abortion: biological and clinical implications. Reprod Biol Endocrinol, 2: 7. 